\title{
ANIMALS EXÒTICS ALS PALAUS REIALS DE BARCELONA'
}

\author{
Anna M. Adroer $i$ Tasis
}

L'afició pels animals salvatges valorats per la seva raresa i valor crematístic ve de molt lluny. Ja existien col-leccions exòtiques a l'antic Egipte, la Xina, l'Índia ${ }^{2}$. Són cèlebres els trofeus de batalles guanyades per Alexandre el Gran, que portava d'Orient i d'Àfrica animals mai no vistos, i els romans presumien de les seves feres en les gàbies - de vegades de plata- dels seus jardins.

Més endavant, els senyors de la baixa Edat Mitjana també es van interessar per aquests animals -i entre ells els nostres monarques -, malgrat que els lleons i altres feres guardades als mateixos palaus comportaven una sèrie de problemes continus i unes despeses enormes de manteniment.

La perillositat d'aquestes bèsties fa pensar que estaven en llocs molt segurs, amb reixes i parets molt sòlides. Com que, d'altra banda, la seva neteja no podia ser gaire eficaç, creiem que més que animals destinats a adornar un ambient eren apreciats pels

' Agracixo a Roser Nos, directora del Museu de Zoologia, la revisió d'aquest treball $\mathrm{i}$ totes les idees $\mathrm{i}$ notes que hi ha aportat.

${ }^{2}$ Gustave Lotsel, Histoire des Ménageries de l'Antiquité à nos jours, París 1912. 
monarques perquè cridaven l'atenció per la seva feresa i la seva potència ${ }^{3}$.

Ens consta que hi havia lleons a Barcelona almenys des del segle $\mathrm{xuI}^{4}$. Sembla que en un principi s'hostatjaven als jardins del Palau Major, sota la muralla, i al segle xIv van ser traslladats a una dependència del Palau Menor o de la Reina.

Els palaus reials Major i Menor, edificats tots dos sobre la vella fortificació romana, existien des de feia molt de temps. Del primer, situat al costat de la Catedral, en desconeixem els orígens, però ens consta que existia ja al segle $\mathrm{X}^{5}$. El Menor va ser construït l'any 1134 pels Templers $i$ va passar per diversos propietaris fins que el 1370 el va adquirir el rei Pere III el Cerimoniós per a la seva esposa Elionor de Sicília ${ }^{6}$.

Si en un principi aquests edificis amb les seves torres defensives semblaven més que palaus, castells fortificats, amb el pas del temps es van urbanitzar uns jardins al seu redós, de manera que sota el Palau Major al peu de la muralla, a l'actual carrer de la Tapineria, s'estenia «l'hort Comtal», que ocupava una part de l'actual via Laitena fins a la desapareguda riera de Sant Joan i la plaça de l'Oli o més enllà. Va ser, potser, en aquest espai on durant un temps es van guardar els lleons.

Al costat del Palau Menor existia «l'hort de la Reina», limitat a ponent pel carrer d'Avinyó i a migdia per la platja i el mar. L'edifici era construit, com ja hem dit, sobre la muralla, i el jardí s'estenia a un nivell més baix. Per salvar el desnivell hi havia uns terraplens coberts d'arbres i plantes? ${ }^{7}$ I, encara que aquest jardí es coneixia pel nom d'hort, era famós perquè era ple de

${ }^{3}$ Nota facilitada per Roser Nos.

${ }^{4}$ E. Carreras Cand, dins Miscelánea histórica catalana, serie II, Barcelona 1918. «Los leones de Barcelona», pp. 57-66.

${ }^{5}$ Anna Maria Adroer i TAsis, El Palau Reial Major de Barcelona, Ajuntament de Barcelona. Delegació de Cultura 1979, p. 15.

${ }^{6}$ F. Carreras Candi, Geografia General de Catalunya. La Ciutat de Barcelona (sense data), p. 420.

${ }^{7}$ Francesc Socies, Llibre de les Fonts de la present Ciutat de Barcelona compost per... Mestre de Cases y de les fonts de la prit. Ciutat en lo any 1650 (manuscrit). 
plantes i animals exòtics, i sobretot perquè al seu costat, en unes voltes de la planta baixa, s'hi hostatjaven les feres.

A més a més d'aquests palaus dintre la ciutat, els nostres monarques posseïen un pavelló de caça a Valldaura, al terme de Cerdanyola, situat en plena muntanya i voltat d'una gran devesa. De temps llunyans existia en aquest lloc una capella dedicada a la Mare de Déu, al paratge on s'havia cregut que havia mort Guifré el Pelós lluitant contra els sarraïns l'any 898. La seva devesa va ser sempre el principal lloc de caça dels nostres monarques als afores de Barcelona, que van passar allí llargues temporades, fins i tot els que no eren caçadors. Tenim noticia que l'any 1346 Pere III el Cerimoniós demanava cérvols a Mallorca per repoblar aquesta devesa i uns anys més tard el seu fill Martí l'Humà feia venir de Saragossa "un cervo e una círvia» per a la devesa de Valldaura ${ }^{8}$.

Però, les notícies més abundants, les tenim sobre els animals exòtics. Els documents ens parlen dels lleons ${ }^{9}$ de Barcelona, i també de moltes altres menes d'animals i espècies: guepards, óssos, galls salvatges, estruços, escurçons, ocells (faisans, falcons, francolins) i dels peixos. Aquestes notícies, extretes gairebé totes dels fons documentals de l'Arxiu de la Corona d'Aragó ${ }^{10}$, ens il-Justren des de l'any 1346 fins al 1445, i encara s'allarguen pel testimoniatge d'un viatger notable, l'alemany Jeroni Münzer, que cinquanta anys més tard va venir a Barcelona, i en un llibre de viatges ens relata meravellat els animals exòtics que posseïa l'infant Enric, nét de Ferran d'Antequera, en el seu magnífic palau situat on es troba ara la plaça de Medinaceli, prop del mar. Les notícies abracen, doncs, del 1346 al 1495, és a dir, un periode de cent cinquanta anys.

L'afició a reunir una col-lecció zoològica era corrent entre els monarques de la baixa Edat Mitjana. La possessió d'aquestes feres era un gran luxe que, al nostre país, només es podien per-

${ }^{8}$ ACA. C. r. 2243 , f. 32 v.

${ }^{9}$ És frequent citar només els lleons quan es parla de les feres en general.

${ }^{10}$ Agraeixo al doctor Frederic Udina i a Mercè Costa, Rafael Conde i Josefina Font, de l'Arxiu de la Corona d'Aragó, la seva ajuda en la lectura dels documents, alguns de dificil interpretació. 
metre les poblacions en les quals el barri jueu havia adquirit una certa importància (Barcelona, Perpinyà, Valècia, Saragossa i Calatayud)" subvencionades a través d'un impost que gravitava sobre l'aljama de la localitat respectiva. La seva manutenció constituīa un problema constant, tant en època de Pere III el Cerimoniós (13361387) com en la dels seus fills Joan I (1387-1396) i Martí l'Humà $(1396-1410)^{12}$.

L'any 1380 l'aljama de Barcelona pagava per la manutenció de cada «bèstia fera» dos sous i set diners cada dia i l'infant Joan (el futur Joan I) ordena als jueus de València que paguin la mateixa quantitat per les feres d'aquella localitat ${ }^{13}$. El rei Pere es mostra un moment preocupadissim quan li comuniquen, l'any 1385, que els lleons de Barcelona són morts, i demana al batlle de la ciutat una informació completa sobre aquest fet $^{14}$. Vol saber-ne la causa, és a dir, si han «mort de fam o de mala cura», perquè tem que no se'ls ha alimentat com es devia i no han menjat la carn que els era necessària, i demana al nunci de Saragossa una informació del que mengen els lleons que són al palau de l'Aljaferia ${ }^{15}$. Aquesta mateixa preocupació la té també uns anys més tard el seu fill Joan I, el qual ordena al veguer que doni el menjar necessari «al leó e al leopart qui són en lo palau de Barchinona», de manera que no es morin de fam. Repetides vegades el rei Joan es preocupa que els animals tinguin

"L. Camó Cabruja, "Los leones de la Ciudad", dins Barcelona Divulgación Histórica, vol. 1 1945, pp. 75-79, i Jordi Ventura, «Los judios en Barcelona durante el s, xıv», dins Destino, 13 març 1965, núm. 1440.

${ }^{12} \mathrm{Si}$ seguim la documentació de l'època, sembla que l'esforç de mantenir aquests animals era superior a les possibilitats dels seus amos. I no sols al nostre país. Uns anys abans, concretament el 1252 , tenim noticia que Enric III d'Anglaterra tenia un ós polar que mantenia a la Torre de Londres, del qual tenien cura $\mathrm{i}$ eren responsables els sheriffs de la ciutat. Perquè no resultés tan cara la seva manutenció es van veure obligats a amarrar-lo amb una forta cadena de ferro i baixar-lo al Tàmesi perquè mengés els peixos que pogués pescar. Wilfred BunN, The Ark in the Park, Londres 1976, p. 16.

13 ACA. C. r. 1660, f. 66.

14 ACA. C. r. 1291 , f. 36.

15 ACA. C. r. 1291 , f. 36 v. 
tot el que necessitin, i sempre es feia difícil d'obtenir diner per a aquesta finalitat ${ }^{16}$.

Com dèiem abans, els jueus pagaven un impost per a la manutenció de les feres, però l'any 1391, amb la destrucció del Call, foren desposseïts dels seus béns. A partir de l'any següent s'ha de buscar, doncs, un altre sistema per trobar els recursos necessaris per a la seva manutenció, i ja que els jueus no poden aportar-los, el rei Joan ordena que, dels honoraris dels alts funcionaris, en siguin deduides algunes quantitats amb aquesta finalitat. O sigui que, a partir de 1392 , seran els funcionaris públics els encarregats del proveiment de les feres, proporcionalment a la quantia dels sous que rebin. El mateix rei en dóna l'exemple i paga dels seus emoluments tres sous diaris ${ }^{17}$.

En un principi només es pagava la manutenció dels animals, però s'havia d'abonar també el sou del lleoner, i l'any 1399 el rei Martí augmenta l'impost dels funcionaris amb aquesta finalitat ${ }^{18}$.

Anys més tard, Ferran d'Antequera (1413-1416) es preocupà de donar a Antoni Barceló, guardià dels lleons i altres animals salvatges, dos sous diaris per al seu manteniment ${ }^{19}$, i establi una graduació entre els funcionaris, de manera que el més antic era l'encarregat de recaptar la moneda necessària. Més endavant, a més d'aquesta recaptació, els lleons vivien dels diners procedents de la venda de les pells dels animals que morien dintre la ciutat ${ }^{20}$ però això comportava molts inconvenients. Finalment, el Consell Municipal acordà fer-se càrrec del sou del lleoner i a partir del segle xvi la col-lecció zoològica passà a ser de l'exclusiva incumbència dels Consellers ${ }^{21}$.

Un dels monarques que més es preocupà per la salut dels animals i també d'enriquir la col-lecció amb noves adquisicions fou

${ }^{16}$ ACA. C. r. 1961 , f. 170 i r. 1964 , f. $103-103$ v, 104 v, 105 i 142.

17 Apèndix Documental, 1.

${ }^{18}$ ACA. C. r. 2242 , f. 114 v.

${ }^{19}$ Apèndix Documental, 11.

${ }^{20}$ Camos Cabruja, "Los leones...", p. 76.

21 Carreras Canor, alos leones.... 3. p. 62. 
Martí l'Humà. Sabem que tenia óssos al Palau Menor ${ }^{22} \mathrm{i}$ $s^{\prime}$ amoinnava molt si no eren ben tractats $\mathrm{i}$ ben alimentats $\mathrm{s}^{23}$. A l'inici del seu regnat el bisbe de Tortosa li féu present d'una lleona "pel jardi de Barcelona»24 i l'any 1404 el monarca demanà al seu primogènit Martí el Jove, rei de Sicília, que n'hi enviés una altra (una lleona "parda») des d'aquella illa llunyana. Per al seu trasllat li trameté vint persones: deu cavallers i deu escuders ${ }^{25}$. Aquest fet indica la complicació $\mathrm{i}$ el dispendi que representava el manteniment d'aquestes feres.

En aquella època, a Navarra, i concretament al castell reial d'Olite, hi havia també uns jardins exòtics considerats com una meravella. Tota mena de plantes hi creixien sobre la muralla reforçada expressament amb grans arcades. L'aigua hi corria abundant $\mathrm{i}$ una lleonera guardava diverses feres. Entre Olite i Barcelona existia un intercanvi, i ens consta que el rei Martí va oferir al rei de Navarra, Carles III el Noble, una lleona i també uns estruços del palau de Barcelona ${ }^{25}$.

Des de sempre els intercanvis i els trasllats eren una cosa corrent i Joan I, per exemple, rebia óssos i també galls salvatges de la Vall d'Aran ${ }^{27}$, malgrat la complicació que, com hem vist, representaven aquests viatges. El trasllat dels animals ha estat sempre una operació complicada i implicava, a més del cost, un risc molt important. Risc pel perill que les feres es morissin pel camí o que ataquessin els qui les portaven ${ }^{28}$.

Però d'aquesta història el que ens causa més estupor és saber que a l'època de Pere III el Cerimoniós, al palau de Barcelona,

${ }^{22}$ Els documents ens parlen d'uns onsos tabach que no hem pogut esbrinar a quina espècie d'animals corresponen exactament. Al diccionari Aguiló hem trobat: «tabach, animal dañino que ataca al ganado en la isla de Mallorcan. (Marian Acunoi Fuster, Diccionari Aguiló, Institut d'Estudis Catalans, Barcelona 1934).

23 ACA. C. r. 2240, f. 40 v.

24 ACA. C. r. 2239, f. 113.

25 ACA. C. r. 2248, f. 29.

26 Juan Ramon Castro, Carlos 111 el Noble de Navarra (1387-1425), Pamplona 1967 , pp. 512 i 526.

27 ACA. C. r. 1952, f. 134 v.

${ }^{28}$ Nota facilitada per Roser Nos. 
s'hi guardaven escurçons. Una nota datada l'any 1381 ens parla de pagar un sou a «na Barthomeua qui pensa dels escurçons e altres bèsties salvatges qui són en lo palau Reyal de Barchinona». Queda clar, doncs, que hi havia escurçons a Barcelona, i si bé no s'especifica en quin dels dos palaus, ens inclinem a pensar que eren al Palau Major, que era el palau reial per antonomàsia. Qui era aquesta Barthomeua que tenia una feina tan especial? Segurament no era pas ella mateixa l'encarregada de tenir cura i alimentar aquestes salvatgines, sinó solament de planejar el seu sosteniment. Diem això perquè altres vegades trobem que el rei es queixa que els lleons es moren de fam i vol saber si per «mala cura o en culpa d'aquell qui els pensavan és a dir, si es moren per culpa de qui els atén, o per culpa de qui els "pensa», de qui realment organitza la seva manutenció. Trobem Barthomeua citada uns anys més tard, el 1390, i continua fent la mateixa feina: té cura dels animals salvatges, però aquesta vegada no se'ns parla d'escurçons, i no sabem si encara vivien: «Na Barthomeua qui pensa de les bèstíes salvatges e aucells qui són en lo nostre palau de Barchinona», diu el rei Joan I. I aquí volem remarcar un fet que ens sembla interessant, i és que a na Barthomeua els reis la tenien en molta consideració: tant Pere el Cerimoniós com Joan I es preocuparen molt que no li faltessin diners, i li pagaven el sou per mitjà de l'oficina del Mestre Racional, que equivaldria avui dia a una subvenció oficial passada a través del ministeri de Finances ${ }^{29}$.

Si com hem dit Pere el Cerimoniós tenia escurçons, aquest fet presenta molts enigmes. De quina manera els guardava? On els guardava? En una gàbia? Amb quina finalitat? En una obra científica del segle xviI se'ns parla d'unes serps blanques que curen les malalties cutànies ${ }^{30}$. És possible que tinguessin poders medicinals?

Però no sols les feres ocupaven un lloc preferent als jardins reials de Barcelona sinó que hi tenien cabuda moltes classes

${ }^{29}$ Apèndix Documental, 11 .

${ }^{30}$ Dr. Clarasol, Singularidades de la Historia Natural del Principado de Catalunya en el s. XVIII, p. 208. 
d'ocells i també els peixos. D'ocells, n'hi havia a tots dos palaus: al Menor, en una gàbia, $s^{\prime}$ hi criaven faisans i francolins" i Martí l'Humà féu construir una gàbia per als ocells del verger del Palau Major i ordenà Joan Caça, que s'ocupava de regar-hi les flors i les plantes, que després de regar tingués cura també «dels aucells $\mathrm{i}$ de totes les altres coses» ${ }^{32}$. També els falcons -que Joan I, tan aficionat a la caça, col-leccionava amb veritable plaer- es guardaven a tots dos palaus, però aquests en unes habitacions determinades, a cura del falconer major, Francesc Bertran ${ }^{33}$.

Martí l'Humà tenia gran afició a criar peixos, i ordenà construir un estany al verger del seu palau amb aquesta finalitat, «que es faci el safareig i que hi posin olles per criar peix» ${ }^{34}$.

Després de la mort del rei Martí (1410), i malgrat l'extinció del casal català, la col-lecció zoològica va continuar: hem vist com Ferran d'Antequera se'n preocupava, i en època d'Alfons el Magnànim, l'any 1445, la reina Maria ens parla del guardià dels lleons del Palau Menor (del «palau petit» com diu ella) a causa d'un litigi entre el porter de l'edifici i el lleoner, per unes habitacions que tant l'un com l'altre volien ocupar dintre de l'edificis'.

Una altra notícia, aquesta també ben extraordinària, ens la proporciona uns anys després el llibre ja citat de Jeroni Münzer ${ }^{36}$, una de les relacions de viatges més importants de l'Edat Mitjana. Aquest alemany, doctor en Medicina, en un periple per la Península Ibèrica durant els anys 1494-1495, arribà a Barcelona i ens ha deixat constància de la visita que féu a l'infant Enric, nét de Ferran d'Antequera ${ }^{17}$, al palau que s'acaba-

31 ACA. C. r. 2239, f. 110.

32 Adroer, El Palau Major..., p. 99.

33 ACA. C. r. 1956, f. 52 v.

34 Adroer, El Palau Major..., p. 99.

35 Apèndix Documental, IV.

${ }^{36}$ Viajes de extranjeros por España y Portugal. Recopilación, traducción, prólogo y notas por G. Garcin Mercadal, Madrid 1952.

${ }^{37}$ Es tracta d'Enric d'Aragó i Pimentel (1445-1522). Fill pòstum de l'infant Enric d'Aragó duc de Villena (germà d'Alfons el Magnànim), i de Beatriu Pi- 
va de construir al costat del convent de Sant Francesc (avui plaça de Medínaceli). La seva narració, traduida, diu així: «Té (l'infant) una casa de tal riquesa que no es creu que pugui ser superada. Totes les habitacions tenen catifes amb figures de colors variats, i les teles són brodades amb or puríssim. Quina casa tan sumptuosa!». I continua: «Allà vam veure un mesquer, animal més gran que una guineu, amb el cap, la boca i les orelles semblants a les de l'ermini, color gris amb taques blanques i fosques, la cua i els peus de gos, animal colèric i furiós ${ }^{38}$. Era una gàbia de fusta subjectada amb una cadena. El seu guardià manà que amb la cadena el lliguessin amb el cap a la gàbia i estirant-lo per les potes del darrera li aixecà la cua, i ens ensenyà el seu membre (perquè era mascle); aleshores li agafà els genitals i els va invertir com qui gira una bossa al revés, deixant a la vista dues cavitats, una a cada testicle; en una d'elles va introduir una cullereta de vidre llis, $i$ en tres vegades va extreure uns dos dracmes d'una substància odorífera amb la qual va untar-me la mà, que va fer olor de mesc durant uns quants dies $»^{39}$.

«Després ens ensenyà un papagai de la grandària d'una gralla o una garça, amb plomes blanques i grises en tot el cos i especialment al coll, com els falcons i els esparvers d'Alemanya; la cua era tan llarga com la d'una gralla, però vermella com el mini, i el bec i les potes eren com els dels altres papagais; parlava també com els altres perquè era un autèntic papagai, encara que d'una espècie diferent dels verds ${ }^{40}$. Finalment ens mostrà un tord d'un color blavós, que segons ens va dir pronunciava

mentel. Comte d'Empúries i duc de Sogorb, fou també lloctinent del Regne de València, del Principat de Catalunya i del Regne de Mallorca. Personatge influente a la cort, vivia luxosament a Barcelona al palau que es féu construir al carrer Ample tocant a l'actual plaça de Medinaceli. (Notes facilitades per Mercè Costa, directora de l'Arxiu de la Corona d'Aragó).

${ }^{38}$ Segons Roser Nos es tractava d'una gineta.

${ }^{39}$ El mesc és una secreció olorosa de sabor amargant produïda pels fol-licles prepucials del mesquer. És emprat en medicina com a antiespasmodic, i també en perfumeria. (Gran Enciclopèdia Catalana).

to Segons Roser Nos es refereix al lloro gris de la Guinea. 
algunes paraules, encara que no el vam sentir parlar mentre nosaltres hi érem".

Fins aquí, les notes que fan referència a la col-lecció reial, per bé que no pensem pas que els animals de l'infant Enric procedissin de la col-lecció dels nostres comtes, sinó que probablement devien formar una col-lecció a part. En aquella època, a tots els grans senyors els agradava la possessió d'animals exòtics pel que representaven de luxe i categoria.

En extingir-se la monarquia catalana, i encara que el càrrec de lleoner fou fins a l'època de l'emperador Carles I de nomenament reial, de mica en mica els consellers van haver d'intervenir-hî i fer-se càrrec dels animals, els quals - com ja hem dit-passaren el mateix segle xvi a ser de la seva exclusiva incumbència.

La ciutat de Barcelona va posseir lleons fins al segle $x v m 1^{4 !}$ i l'anomenada Casa dels lleons, una dependència del Palau Menor, no desaparegué fins al 1860, quan va ser enderrocat l'edifici per procedir a l'obertura de l'actual carrer de la comtessa de Sobradiel.

41 Antonio de Bofarult, Guia-Cicerone de Barcelona, Barcelona 1847, p. 40. 


\section{APÈNDIX}

1392. Barcelona 18 gener

El rei Joan al veguer de Barcelona:

Com nos per raho de la destruccio de la aljama dels juheus de Barchinona la qual aljama per manament e ordinacio nostra solia pagar la provisio dels leons e leopars nostres de Barchinona, haiam ordonat que nos dels emoluments del offici a nos comanat donesses e pagasses cascun jorn a Johan de Verdexo leoner nostre tres solidos barchinonenses del cinque dia del mes d'agost prop passat que fou la dita destruccio tro al present dia e d'aqui avant cascun jorn...

ACA. C. r. 1963 , f. 17 v.

II

1415. Barcelona 16 febrer

Sic omnibus notum etc. Ego Anthonius Barcalo civis barchinone custos sunt alimentator leonum et aliorum animalium silvestrium que in palatio minori vocato de la Reyna Civitatis Barchinone detinentur, per provisionem inde michi factam per Serenissimum dominum Regem cum sua patenti littera huismodi serie: Nos Ferdinandus dei gratia Rex Aragonum Sicilie et Valentie Maiorice Sardinie et Corsice Comes Barchinone dux Atenarum et Neopatrie ac etiam Comes Rossilionis et Ceritanie confidents de fide et sufficiencia vostri fidelis nostri Antohoni Barceloni Civis Barchinone tenore presetis comittimus sive comendamus vobis ad regie dignitatis beneplacitum officium alimentatoris leonum et aliorum animalium silvestrium que in palatio minori vocato de la Reyna civitatis Barchinone detinentur vos ergo dictus Anthonius memoratum officium teneatis regatis ac circa danda debita etiam necessaria alimenta dictis animalibus et la diligentia que convenit intendatis. Et habeatis pro dicta provisione fienda ommes et singulas peccunia quantitatis provisioni dictorum animalium assignatas preceptis duobus solidis cotidianis monetis Barchinone de terno qui operibus palacii veteris dicte Civitatis serverunt assignati et quiquidem duo solidi exsolvantur videlicet ex illis decem octo denariis barchinonensis qui dandum (?) super juribus terciorum curie vicarii et per illas sex denaris dicte monete qui super emolumentis officii capitas escubiarum Regis dicte civitatis facerunt olim provisioni dictorum leonum et 
animalium assignati. Mandantes de certa sciencia et expresse vicario subvicario baiulo mustaçaffo alisque officialibus barchinone tam presentibus quam futuris de quorum officii sive emolumentis illorum fuerunt usque nunc dicte quantitatis peccunie exsolute quatenus easdem per terminos sive solutiones assuetas et debitas exceptis dictis duobus solidis operum premissorum vobis aut cui volueritis vestri loco tribuant quandam memorantum tenueritis officium et exsolvant et solutionibus recuperent apocas in prima quarum tenor huiusmodi sit insertis in aliis vero de eadem specialis mentio habeant. Quare Nos mandamus magistro rationali curie nostre et alii quicumque a dictis officialibus compotum audituro quatenus tempore racionii eorundem ipsis ponente in dictis quantitatis peccunie quas vobis exsolverint in vim huius et restis apochas supradictas eadem in ipsorum compotis reccuperant et admittent nec ullum super eis dubium vel questionem faciant vel opponant in cuius rei testimonium presentem fieri iussimus pendenti nostro sigillo munitam, datum Cesarauguste vicesima septima die febroarii anno a Nativitate domin $\mathrm{M}^{\circ}$ CCCCXIIII Regnique nostri tercio Rex Fferdinandus, Confiteor et recognosco vobis Anthonio Xanxis civi capitique excubiarum civitatis Barchinone racione sex denariorum Barchinone quos qualibet die quolibet caput excubiarum dicte civitatis dare et solvere tenetur custodi dictorum leonum et aliorum animalium pro provisione eorum solvistis michi pro uno anno qui sum et XXVIII presentis mensis ffebroari novem libras monete barchinone de terno. Et ideo renunciando excepcioni non numerate et non solute peccunie et dolo malo in testimonium premissorum presentem vobis facio de predictas novem libras apoca de soluto. Actum est hoc barchinone XVI mensis ffebroari anno a Nativitate domini $\mathrm{M}^{\circ} \mathrm{CCCC}^{\circ}$ XV. Signum Antoni Barçelo predicti qui hoc laudo et firmo.

Testes huius rei presentes Petrus Matheus mercator et Bernardus Noves scriptor Barchinone.

AHPB, Notari Pere Pellicer, Manual 2-VII-1414 26-VI-1415 (lligall 8), sense foliar

1381, Barcelona, desembre

Item donc a na Barthomeua qui pensa dels escurçons e altres besties salvatges qui son en lo palau Reyal de Barchinona, los quals li eren deguts ab albara d'escribà de ració, scrit en Çaragoça derer dia del mes de maig del any MCCCLXXXI per rahó de albara se conté que cobre (quantitat illegible). 
Al marge: CV sous de Barchinona.

(Aquest albarà és copiat del llibre del Mestre Racional de l'any 1381, que tracta dels pagaments fets per Pere dez Vall, conseller i tresorer del Rei).

ACA. R. P. Mr. r. 375, f. 195.

1390, Saragossa 7 desembre

Lo Rey:

Molt car frare. Segons que havem entes a na Barthomeua qui pensa de les besties salvatges e aucells qui son en lo nostre palau de Barchinona, es degut de sa quitacio e provisio de les dites besties. E ço vullam que ji sia pagat de la part a nos pertanyent en los emoluments del offici de la governacio General a vos comenat. Pregam e manam vos car frare que la dita part nostra façats encontinent pagar a la dita Barthomeua tot ço que degut li sia per les rahons dessus dites segons que.n serets informat per en Bernat Buçot scriva de Racio de casa nostra e en altra manera en veritat ho trobarets. Com nos vullam de certa sciencia que axi-s faça. Dada en Çaragoça sota nostre segell secret a VII dies de decembre del any MCCCXC. Rex Johannes.

Dirigitur: domino duci Montis albi.

Aquests dos documents $\mathrm{i}$ molts altres van ser cedits fa molts anys per Josep Ros de Ramis (a.C.s.), quan jo preparava la tesi sobre el Palau Major, i fins avui no he tingut ocasió de publicar-los. Des d'aquí agraeixo la seva generosa col-laboració.

ACA. C. r. 1958 , f. 154 v.

\section{IV}

1445. València 19 d'octubre

Pro Gundissalvo del Castel, portario.

Maria etc. Al amat Conseller del senyor Rey e nostre, mossen Johan de Corbera Cavaller e batle general per lo dit senyor en lo principat de Cathalunya, Salut e dileccio.

Per part de Gonçalbo del Castell porter del vostre offici, nos es fet clamor dient que jat sia per mossen Galceran de Requesens vostre predecessó en lo dit vostre offici hagues donada al dit Gonçalbo una casa dins lo petit palau que s.enderrocava perquè la obras, e habitas en aque- 
lla, a fi que fos pus prest e prompte a servir son offici, attes lo dit vostre offici se te en casa aixi mateix del dit palau e afixa a aquell. E lo dit Gonçalbo haia obrada la dita casa e habitat e habita en aquella servint pus promptament lo dit offici que si habitas en altra part. Ara pero novament N'Antoni Barcelo garda dels leons del dit palau, ha obtenguda una letra de nostra cort subrepticiament e obrepticia manant que la dita casi li sia donada e paguada la obra que ha feta plus ha de XXXV anys en una sala del dit palau. E com sobre les dites coses vullam sia provehit degudament $\mathrm{e}$ les parts hoydes com algu no si dega esser tret de sa possessio sens coneguda, dehim, manam e cometem a vos que si atrobarets ab veritat les dites coses aixi passar com dessus es dit, permetats la dita nostra letra o provisio esser deduhyda a execucio ans aquella no obstant hoydes les parts hi ministrets justicia, procehint hi de paraula e sens scrit attes les dites parts son totes familiars del dit senyor. Car nos sobre les dites coses a cautela vos donam e comanam totes nostres veus e poder. Dada en Valencia a XVIIII dies del mes de octubre en l.any de la Nativitat de Nostre Senyor Mil CCCCXXXXV. La Reyna.

ACA. C. r. 3195 , f. 89 v. 